WwW.jmscr.igmpublication.org
Impact Factor 3.79

ISSN (e)-2347-176x

crossref DOI: _http://dx.doi.org/10.18535/jmscr/v3i9.57
Journal Of Medical Science And Clinical Research

IGM Publication

An official Publication of IGM Publication

\title{
Clinical Profile of Anemia in Elderly population
}

\author{
Authors \\ Dr Pradnya Diggikar ${ }^{1}$, Dr P.K.Satpathy ${ }^{1}$, Dr Kanishka Jain ${ }^{2}$, Dr Puneet Bhuwania ${ }^{2}$ \\ Dr Deepak Baldania ${ }^{2}$, Dr T.Venu Babu ${ }^{2}$, Dr Anuja Patil ${ }^{2}$, Dr Prafull Chahjjed ${ }^{2}$ \\ ${ }^{1}$ Professor Department of Medicine, ${ }^{2}$ Resident Department of Medicine
}

\begin{abstract}
Background:-Anemia is a common concern in older people and can have significant morbidity and mortality. Because anemia is a sign, not a diagnosis, an evaluation is almost always warranted to identify the underlying cause

Methods:- Cross sectional hospital based study was carried out, of elderly patients with history of anemia for 1 yrs duration. Each patient was screened for anemia. Standard protocols were used to make diagnosis of anemia.

Results: Out of 100 elderly anemic patients, 55 were females and 45 were males. 28 patients had microcytic anemia, 62 patients had normocytic anemia. 6 patients had macrocytic anemia. Two patients who had pancytopenia picture and two patients had dimorphic picture. Normocytic anemia was the most common blood picture in patients having an underlying malignancy. Microcytic anemia was the next common picture,

Conclusions: Failure to evaluate anemia in elderly could lead to delayed diagnosis of potentially treatable conditions. Nonspecific symptoms like fatigue and weakness should not be ignored in the geriatric population as they could be important pointers towards presence of anemia in these patients. An effort should always be made to reach etiological diagnosis before instituting specific therapy.
\end{abstract}

\section{Introduction}

Anemia (French for an-not and haem - blood) is considered to be present if the $\mathrm{Hb}$ concentration or hematocrit is below the lower limit of the $95 \%$ reference interval for individual's age sex and geographic location. ${ }^{(1)}$

The World Health Organization (WHO) recommends that anemia should be considered to exist in adults who's Hb levels are lower than 13 $\mathrm{gm} / \mathrm{dl}$ (males) or $12 \mathrm{gm} / \mathrm{dl}$ (females). Any of the three measure of concentration (hemoglobin, Hematocrit, or number of red cells) may be used to establish the presence of anemia, but the blood hemoglobin concentration is often preferred, in part because it is the value most indicative of the pathophysiologic consequences of anemia.

\section{RED CELL COUNT}

Male $-5.0 \pm 10^{12} / 1$

Female $-4.3_{ \pm} 0.5_{\mathrm{x}} 10^{12} / 1$

Haemoglobin

Male $-15_{ \pm} 2 \mathrm{~g} / \mathrm{dl}$

Women $-14_{ \pm} 2 \mathrm{~g} / \mathrm{dl}$

PCV

Male $-0.45_{ \pm} 0.005(1 / 1)$

Women - $0.41_{ \pm} 0.04(1 / 1)$

Anemia is not a disease in itself, but a vital and sometimes lone indicator of an underlying 
pathology. Anemia and its manifestation or anemia complicating the course of another illness can bring the patients to medical attention. So, the correct diagnostic terminology for a patient of anemia requires the inclusion of underlying cause of anemia in order to exhibit correct treatment.

Anemia is a common concern in geriatric age group. In this population, it can have significantly more severe complications than in the younger adults and can greatly hamper the quality of life (3).

The aim and objectives of the study are:-

a) To study the clinical profile of anemia in geriatric population

b) To determine the various types of anemia and correlate with clinical presentation.

c) To determine the aetiologies of anemia with particular reference to this geriatric semiurban population.

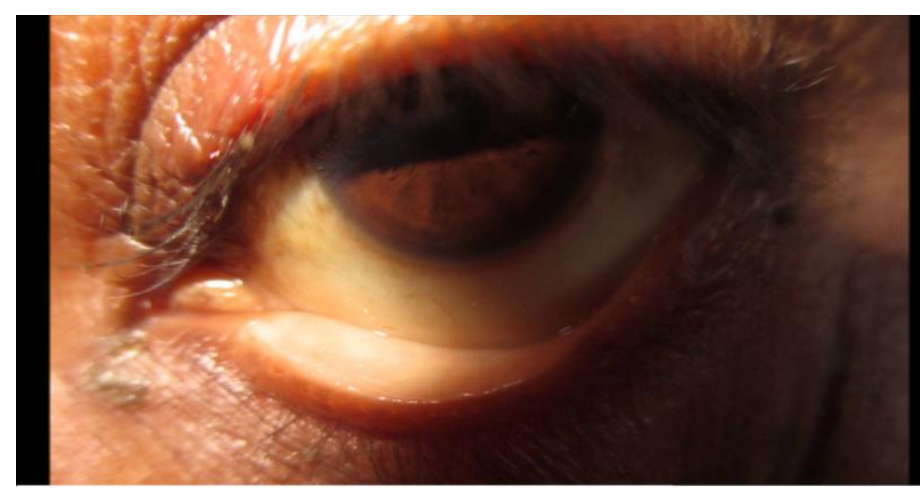

Figure 1:- Pallor as demonstrated on Patient.

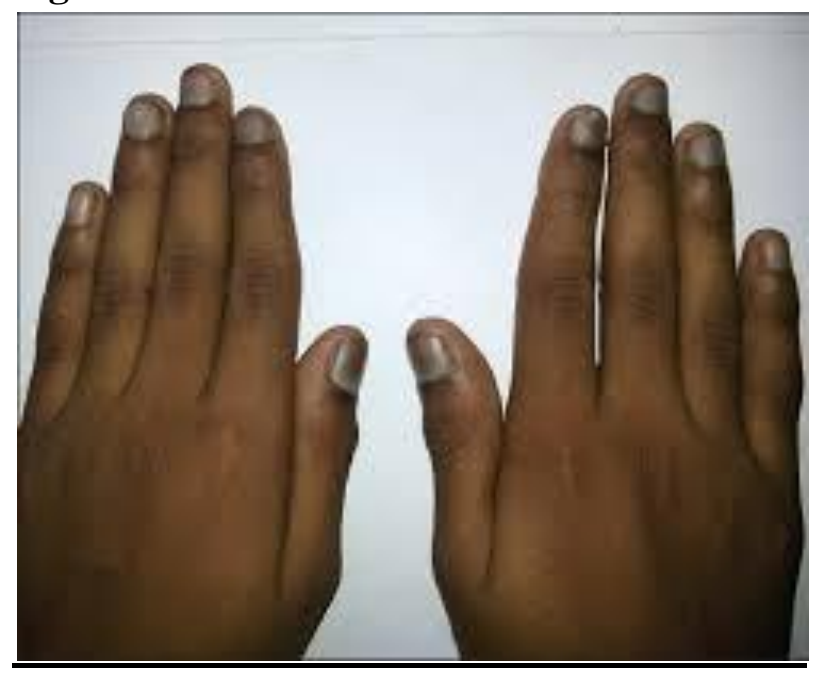

Figure 2 Knuckle Pigmentation sign of anemia

\section{Material and Methods}

The present study included analysis of hundred consecutive patients of anemia.

An observational cross sectional study was carried out on patients aged 60 years and above (either sex) presenting to our hospital fulfilling the WHO criteria of anemia (haemoglobin $\mathrm{Hb}<13$ in males, $\mathrm{Hb}<12$ in females) ${ }^{(4)}$

A detailed history was taken regarding the nature and duration of symptoms and detailed clinical examination was done.

Patients presentations ranging from easy fatiguability, lassitude, breathlessness, palpitations, chest pain, swelling of feet/ anasarca, rashes, petechiae, purpura, bone pain, joint pain, leg ulcers, fever, paraesthesia, difficulty in walking, unsteadiness and history of malena as well hematemesis were sought and included in the study.

In general examination pallor of the conjunctiva and oral mucosa was looked for. Atrophy of filiform papilae of the tongue, cheilosis, platynychia, Koilonychia of the nails and Knuckle pigmentation were looked for and assessed in relation to other features. Pedal edema and evidence of cardiac failure were noted. Fever when present was evaluated for the cause.

In systemic examination the cardiovascular system finding were studied particularly hemic murmur, venous hum. Abdominal findings of hepatomegaly and splenomegaly and ascites were noted. Evidence of respiratory infections and neurological dysfunction specifically dorsal column sensory loss in suspected megaloblastic anemia were investigated. Per rectal examination wherever indicated. Fundoscopy was done to detect optic atrophy.

The following hematological investigations were carried out for all patients1 .

a) $\mathrm{Hb}$, Mean corpuscular volume (MCV), Mean corpuscular hemoglobin concentration (MCHC), mean corpuscular hemoglobin (MCH), 
packed cell volume (PCV), reticulocyte count,

peripheral smear for RBC cell morphology, premature cells, blast cells and malarial parasites.

b) Total leucocyte count (TLC), differential leucocyte count (DLC),

c) Erythrocyte Sedimentation Rate (ESR),

d) Platelet count

e) Serum LDH

f) HbElectrophoresis in selected patients.

2. Blood urea, serum creatinine

3. Serum ferritin where indicated.

4. Bone marrow studies (aspiration/biopsy) were carried out in Patients with blood smear showing immature white cells or nucleated red cells.

5. Vitamin B12 and folate assays were done for dimorphic and macrocytic

6. Additional investigations

a) Chest X-ray

b) ECG

b) Ultrasonography (USG) of abdomen and pelvis

c) Stool for parasites and occult blood.

d) Computed tomography (CT)/magnetic resonance imaging (MRI) in suspected malignancy cases.

e) Upper gastrointestinal (GI) endoscopy

Upper GI endoscopy was done for patients with upper GI bleed.

Patients were also evaluated for an underlying malignancy if there was suspicion of the same, based on clinical symptoms, laboratory parameters or imaging studies.

\section{RESULTS}

Age and Sex Distribution of 100 Geriatric Patients shown in Table 1.

Table 1

\begin{tabular}{|l|c|c|c|c|}
\hline $\begin{array}{l}\text { AGE (in } \\
\text { Years) }\end{array}$ & Male & Female & Total & Percentage \\
\hline $61-65$ & 18 & 22 & 40 & $40 \%$ \\
\hline $66-70$ & 14 & 18 & 32 & $32 \%$ \\
\hline $71-75$ & 8 & 6 & 14 & $14 \%$ \\
\hline
\end{tabular}

\begin{tabular}{|l|c|c|c|c|}
\hline $76-80$ & 4 & 5 & 9 & $9 \%$ \\
\hline $81-85$ & 1 & 3 & 4 & $4 \%$ \\
\hline 86 or more & 0 & 1 & 1 & $1 \%$ \\
\hline TOTAL & 45 & 55 & 100 & $100 \%$ \\
\hline
\end{tabular}

In our study population, age of patients ranged from 60 to 87 years.

The maximum numbers of patients were in the age group 60-69 years.

Of which $45 \%$ were males and $55 \%$ females as shown in table 1.

Table 2 Presenting Symptoms

\begin{tabular}{|l|c|c|}
\hline Symptom & $\begin{array}{c}\text { No. Of } \\
\text { Patients }\end{array}$ & Percentage \\
\hline Fatigue & 70 & $70 \%$ \\
\hline Palpitations & 11 & $11 \%$ \\
\hline Anorexia & 11 & $11 \%$ \\
\hline Breathless on Exertion & 5 & $5 \%$ \\
\hline Others & 3 & $3 \%$ \\
\hline
\end{tabular}

The most frequently encountered symptom was fatigue seen in $70 \%$ of patients the next most commonly seen symptoms were palpitations and anorexia seen in $11 \%$ of patients, while few patients' symptoms overlapped.

Table - 3 Signs

\begin{tabular}{|l|c|}
\hline Signs & No.of Patients \\
\hline Pallor & 66 \\
\hline Pedal edema & 20 \\
\hline Glossitis & 6 \\
\hline Lymphadenopathy & 2 \\
\hline CHF & 8 \\
\hline Hepatosplenomegaly & 2 \\
\hline
\end{tabular}

The two patients that had hepatosplenomegaly both turned out to be cases of ( $\underline{\mathrm{CML}}$ ).

Most patients (68\%) were taking some form of medication the most common among them was NSAIDS. 
Table 4 :-Types of Anemia

\begin{tabular}{|l|c|}
\hline PBS Findings & No.Of Patients \\
\hline Normocytic & 62 \\
\hline Microcytic & 28 \\
\hline Dimorphic & 2 \\
\hline Megaloblastic & 6 \\
\hline Pancytopenia & 2 \\
\hline
\end{tabular}

It was also detected that the most common anemia encountered among these patients was Normocytic Normochromic.

\section{Table 4}

\begin{tabular}{|l|c|}
\hline Bone Marrow Findings & No. of Patients \\
\hline Iron Deficency & 4 \\
\hline Aplastic & 1 \\
\hline Dimorphic & 4 \\
\hline Hypercellular & 2 \\
\hline Megaloblastic & 4 \\
\hline Chronic Leukemia & 2 \\
\hline
\end{tabular}

Table 5 : Aetiology of Anemia

\begin{tabular}{|l|c|c|}
\hline Aetiology & Male & Female \\
\hline Blood Loss & 12 & 18 \\
\hline Nutritional & 14 & 22 \\
\hline Chronic Leukemia & 1 & 1 \\
\hline Upper GI Malignancies & 1 & 0 \\
\hline Chronic Renal Failure & 5 & 6 \\
\hline Liver Disease & 7 & 2 \\
\hline Tuberculosis & 2 & 3 \\
\hline Aplastic Anemia & 2 & 2 \\
\hline Hemolytic Anemia & 1 & 0 \\
\hline Total & 45 & 55 \\
\hline
\end{tabular}

The most common etiology was nutritional among the study population.

Blood loss was the next most common etiology.

Three patients were detected as malignancy while Renal Disease was detected in 11 patients.

\section{Discussion}

The most common cause of anemia worldwide in elderly is anemia of chronic disease ${ }^{[6]}$. Iron deficiency is frequently seen in elderly, typically as a result of chronic blood loss through GIT [5]. Vitamin B12 deficiency, folate deficiency, MDS are among other causes of anemia in elderly ${ }^{[7]}$. Literature has revealed that ageing does have an effect on blood production with reduced ratio of bone marrow to fat cells and reduced marrow response when stimulated with erythropoietin ${ }^{[8]}$. However, the decline of hemoglobin and concomitant increased anemia with age should not be presumed to be a result of "normal aging" or due to nutritional deficiency and blanket treatment with hematinics should be avoided. Detection of anemia in an older person should prompt appropriate clinical attention.

There were 45 males and 55 females which correlates to a study conducted in south india by Dr.Bhasin ${ }^{[9]}$.

The frequency of symptoms in our study were studied.

Fatigue was the most common symptom comparable to previous studies.

\begin{tabular}{|l|l|l|l|l|}
\hline Title of Study & Author & Year & $\begin{array}{l}\text { No. } \\
\text { Cases }\end{array}$ & Fatigue \\
\hline Iron deficiency anemia in people aged 65 years and older: & Chebbi W & 2014 & 102 & $70 \%$ \\
\hline $\begin{array}{l}\text { Characteristics of Anemia in Elderly: A Hospital Based } \\
\text { Study in South India }\end{array}$ & DrBhasin & 2011 & 100 & $71 \%$ \\
\hline An Etiologic Profile of Anemia in 405 Geriatric Patients [10] & $\begin{array}{l}\text { DrTabea } \\
\text { Geisel }\end{array}$ & 2014 & 405 & $30 \%$ \\
\hline
\end{tabular}

Palpitations were seen in $11 \%$ of patients and Anorexia seen in $11 \%$ patients while Dyspnea was seen in $5 \%$ of patients on presentation which correlates well to Dr Bhasin's Study ${ }^{[9]}$ done in a tertiary care hospital in South India.
In a study Dr.K.V.Krishnadas ${ }^{[11]}$ the predominant symptoms were realted to cardiovascular symptoms. However he concluded that symptomatology is so diverse that any symptoms can occur. Correction of $\mathrm{Hb}$ levels is required 
before the judgement on the significance of these symptoms in relation to more serious illness can be made.

The most common etiology was Nutritional seen in $36 \%$ followed by Blood loss seen in $30 \%$ of cases, which correlates well to Dr Bhasin's Study [9].

Where in western countries Anemia of Chronic disease like (CKD) is most common as stated in the study done by DOUGLAS L. SMITH in University of Wisconsin ${ }^{[12]}$.

11 cases of CKD were detected in our study.

The most common type of anemia was normocytic normochromic.

This correlates well to Dr Bhasin study ${ }^{[9]}$

His study showed that $62 \%$ of patients had normocytic anemia while $30 \%$ had microcytic picture and 2 patients had macrocytic and pancytopenia pictures.

\section{Conclusion}

Failure to evaluate anemia in elderly could lead to delayed diagnosis of potentially treatable conditions. Nonspecific symptoms like fatigue and weakness should not be ignored in the geriatric population as they could be important pointers towards presence of anemia in these patients.

There is a wide spectrum of manifestations of anemia both in type and aetiology amongst geriatric population, the commonest type being normocytic normochromic and aetiology nutritional underlying malignancy was noted in only 3 cases.

An effort should always be made to reach etiological diagnosis before instituting specific therapy.

More studies are required to find out the incidence and prevalence of anemia amongst geriatric population.

\section{References}

1. DacieJ.V. and Lewis S.M. Practical Haematology.200610 ${ }^{\text {th }}$ Edition Churchill livingstone.Edinburg.
2. World Health Organisation Tech Rep Ser 580, 1975

3. AniaLafuente BJ, Fernandez-Burriel Tercero M, Suarez Al- menara JL, Betancort Mastrangelo CC, Guerra Hernandez L (2001) Anemia and functional capacity at admission in a geriatric home. An Med Interna18(1):9-12

4. World Health Organization. Definition of an older or elderly person. http://www.who.int/healthinfo/survey/agei ngdefnolder/en/ index.html. Retrieved August 29, 2010

5. Mary Lynn R, Sutin D (2003) Blood disorders and their man- agement in old age. In: Geriatric medicine and gerontology. Churchill Livingstone, Edinburg, pp 1229-1230

6. Davenport J (1996) Macrocytic anemia. Am Fam Physician 53(1):155-162

7. Varat M, Adolph R, Fowler N (1972) Cardiovascular effects of anemia. Am Heart J 83:415-426

8. Mehta BC (1999) Iron deficiency anemia. In: Shah S, Anand M (eds) API textbook of medicine, 6th edn. Association of Physicians of India, Mumbai

9. Characteristics of Anemia in Elderly: A Hospital Based Study in South India Amit Bhasin and Medha Y. Rao Indian J Hematol Blood Transfus. 2011 Mar; 27(1): 26-32.

10. An Etiologic Profile of Anemia in 405 Geriatric Patients TabeaGeiselAnemia. 2014; 2014: 932486.

11. Das KV. Study of pattern of anemia in hospital inpatients at the medical college hospital , Trivandrum Indian J. of Med Science 1992; 485: 48

12. Douglas Smith. Anemia in the Elderly University of WisconscinAm Fam Physician. 2000 Oct 1;62(7):1565-1572. 